\title{
El emplazamiento de la memoria colectiva: Crónica Psicosocial
}

\author{
Pablo Fernández Christlieb \\ Universidad Nacional Autónoma de México
}

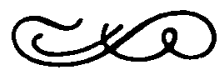

\section{LA SOCIEDAD SEGUN GRAHAM BELL VS. LOS ESPACIOS COMUNICATIVOS}

Existe la creencia no dicha de que la civilización empezó el mismo día que el teléfono, por lo que se supone que toda la cultura anterior a la línea telefónica está hecha, como Dios al revés, a su imagen y semejanza, según el modelo emisor-canal-receptor, que es el modelo de la información, útil para transmitir mensajes y para producir en serie: algo entra por un extremo de la línea y sale por el otro. La revolución informática ha puesto de moda el tema de la comucicación, pero, bajo el lema de que todo lo que existe es nuevo o por lo tanto no existe, la comunicación es vista como si fuera información, sólo que pasmosamente más rápida y sobre todo más vistosa, puesto que aparece en pantallas como las de las computadoras: el apantallamiento.

La información, como en los canales de radio o televisión, camina en una sola línea porque de otra manera se pierde, como cuando hay estática, ruido o se cruzan las líneas del teléfono. Sin embargo, quizá sea lamentable para muchos comunicólogos enterarse de que la comunicación existe antes que los teléfonos, y la cultura, la civilización y la historia, también, por lo que se tuvieron que hacer con otro modelo, anterior al invento de los canales, las líneas y otras formas de la primera y segunda dimensión, del punto y la raya de Morse y el telégrafo: se construyeron con el modelo de un espacio de tres o cuatro dimensiones, donde cupiera la gente, las cosas, todo; incluso el tiempo y la memoria.

En el espacio de la comunicación caben las palabras, pero también los gestos como las sonrisas y los contactos como los besos, o los ceños fruncidos y los golpes, las cosas como los muebles y los semáforos, los lugares como las azoteas y las esquinas, y los huecos como el clima y el silencio. Todo lo que existe en el espacio es comunicativo, y al revés de la información, que es una vía de tránsito, la comunicación es una estancia que puede acumular objetos: tiene memoria; de suerte que lo nuevo y lo viejo forman igualmente parte de la comunicación que se lleva a cabo en cualquier lugar. La cultura, tanto la alta cultura 
como la cultura menor y cotidiana están contruidas de comunicación; cultura es la forma de entender el mundo, y por lo tanto, es la forma de pensar y sentir; así que si se acepta que la música es cultura, que la arquitectura es cultura, que la escultura es cultura, que los diseños de automóviles y la producción de modas también lo son, tendrá que aceptarse que son igualmente una forma de pensar y de sentir: que son comunicación.

Y la mayor parte de la cultura contemporánea es memoria colectiva, esto es, construcción y distribución de espacios logrados poco a poco. Pensamos y sentimos de memoria: uno cierra la puerta de su cuarto y se queda a solas porque hace doscientos años se decidió que ahí tenía que haber una puerta para cerrarse tras uno, y uno quedarse a solas. La cantidad de infelices solitarios que ha producido esta mínima tradición es desconocida, pero en todo caso, el espíritu colectivo vive en los espacios que se han construido desde hace tiempo, y se comunica con ellos, sin saber mucho qué es lo que comunica, porque de eso no ha sido informado: la comunicación colectiva es lo que no está en la información masiva.

\section{PRIMER EMPLAZAMIENTO: LAS PLAZAS Y LAS CALLES}

Los verdaderos modos de comunicación de masas no pasan de cinco, y ninguno de ellos es la televisión, y tampoco ninguno es novedad de nuestro tiempo. El primero es griego y se llama plaza pública, que tiene físicamente la forma de la comunicación, porque es un lugar plano, amplio, abierto y que produjo, entre otras cosas, la democracia; la democracia es estrictamente un estilo de comunicación - la monarquía podrá ser otro, pero no cabe en una plaza pública-. Puesto que la comunicacón es un fin en sí mismo en tanto que no sirve para nada excepto para comunicarse, o sea, para entender la vida, y encontrarle algún sentido que haga que valga la pena vivirla, y hasta hoy el único encontrado ha sido la comunicación misma, así el espacio público queda privilegiado sobre los espacios privados (1), que, no obstante ser inútiles para eso de encontrarle sentido a la vida, son necesarios para hacer otras cosas como dormir o lavarse. Por ello, alrededor de la plaza pública tienen que aparecer las calles para ir a las casas a dormir, de suerte que aquí se inicia la posibilidad de un espacio menos público, y en consecuencia, las calles se van angostando, quebrando, ensuciando, a medida que se alejan de la plaza pública: el espacio se va haciendo más privado, y mientras más angosta y alejada sea la calle, más se pueden hacer cosas privadas, cosas que no son de interés general, como rascarse la nariz, acto que, en rigor, no puede hacer grandes contribuciones al mejoramiento de la democracia.

Las calles forman un área menos pública dentro del espacio público, y la Edad Media se encarga de desarrollarlas, desde la plaza principal donde se llevan a cabo festividades, torneos y teatros, hasta los callejones torcidos y estrechos. La mejor parte de la Edad Media, que los renacentistas llamaron gótica para despreciarla, presenta la forma más perfeccionada de la calle hasta hoy día: hecha sin planos, sigue la lógica de las necesidades de la gente de encontrarse y desencontrarse a cada rato, como jugando escondidillas, para así volverse a saludar y a juntar y a platicar. $Y$ es que la ciudad medieval tiene el urbanismo del laberinto (2) y la arquitectura de la sorpresa, como lo muestran sus calles y catedrales. Las calles se mueven al compás de la gente y si, como dice Witt- 
genstein, «la arquitectura es un gesto», el gesto gótico ha sido el más parecido al que utiliza la gente para estar cerca unos de otros, y que el urbanismo contemporáneo no ha logrado hacer. Y por lo mismo, las casas y la vida bajo techo nada más cumplen la función biológica de protección contra la intemperie; son un cobijo natural, como la ropa y la piel, pero no un lugar de vida social: las puertas y las ventanas se cierran para resguardarse de los elementos, no de los demás.

Lo que sí se perdió durante el medievo fue la forma pública de autogestión de la colectividad, pero, en todo caso, el espacio público urbano en su conjunto - calles y plazas-, como lugar del espíritu colectivo, reúne lo público y lo privado, la razón y la pasión, lo culto y lo ignorante, el chisme y el dogma, las reglas y la desobediencia, el esplendor y la miseria, las muertes y los nacimientos, en fin, todos los eventos de la vida: toda la comunicación junta en un mismo espacio.

La oscuridad presunta de la Edad Media puede resumirse en el hecho de que las dificultades de la vida, el enorme trabajo de la mera sobrevivencia, provocan que el espacio público urbano, como modo de comunicación, se agote, se canse, dé de sí; como si el aire de la calle se hubiera hecho lento, como si se hubiera cuajado; como si la atmósfera fuera de gelatina. El rey más culto de su tiempo, Carlomagno, no logró, por más que quiso, aprender a escribir. La riqueza que trajo la revolución mercantil a partir del siglo XIII, además de romper el espacio medieval, permite que haya un intento de revitalizar la cultura y la comunicación, pero puesto que la calle se había vuelto un lugar tan homogéneo, tan repetitivo, donde lo que se comunicaba ya era siempre lo mismo, este intento tiene que darse por otra vía.

\section{SEGUNDO EMPLAZAMIENTO: LA CALLE CONSTRUYE SU CASA}

Hay diversas maneras de empezar a hablar de la Edad Moderna; la más simpática dice que la modernidad se inicia con la toma de Constantinopla por los turcos en el año de 1453. Entre las otras, se puede decir que empieza con el invento de los libros de contabilidad, que a todo le pusieron precio; o con la fundación de los museos, que mezclan objetos de todo tipo; o con el alineamiento de las calles para que pasen carruajes, porque el poder no sabe andar a pie; o con el desarrollo de la perspectiva en el dibujo, porque permite ver el mundo desde un ángulo distinto al de los demás (3). O también, la Edad Moderna se inicia el día en que se cerraron las puertas de las casas aunque no hiciera frío, porque tras ese portazo se funda un nuevo espacio comunicativo: el espacio privado doméstico, o más domésticamente, la casa. No es fortuito, por caso, que Brunelleschi haya tenido entonces la ocurrencia de hacer muros que no sirvieran para detener techos, sino nada más que para ser vistos, o para que no sea visto lo que está detrás, es decir, para separar un espacio de otro; la arquitectura contemporánea de Luis Barragán utilizó poéticamente esta idea: el muro como creación de un sentimiento de soledad íntima.

La casa, en su versión fundamental, es una cocina equipada con camas, porque es alrededor de la lumbre donde se gesta su comunicación: la palabra «hogar» se refiere concretamente a ese fuego donde se hace la comida, se calienta el aire y se desentumece el cuerpo. La gente se reúne en la cocina y allí platica sobre los asuntos de la colectividad, pero lo hace desde, literalmente, la perspec- 
tiva de la casa, por lo que ésta se inventa como lugar de creación de diferencias que contribuyan a un mundo necesitado de pluralidad. La cocina es, desde entonces, la plaza pública de la casa, y donde se cocieron, entre otras cosas, las ideas del Renacimiento. En efecto, la creación de la casa como espacio comunicativo no obedece a deseos de apartarse de la vida pública, sino por el contrario, a la necesidad de enriquecerla: por eso la calle traslada el centro de la vida social a la casa. Incluso los centros de gobierno como principados o ducados, las casas comerciales, o la Iglesia, se pueden considerar como otras tantas casas, porque el poder y las relaciones políticas, económicas o artísticas se ejercen con las leyes de la comunicación doméstica: Miguel Angel o Leonardo provienen del espacio doméstico, y salen de sus casas para ir a trabajar a la casa de los Medicis, o a «la Casa de Dios», que por el momento también era la de Lucrecia Borgia. El hecho de que los príncipes tuvieran por casa a la ciudad entera no cambia el espacio (4).

Sin embargo, después de un par de siglos de vivir entre cuatro paredes, la casa debe resultar muy estrecha para la mayoría, y puesto que ya existían las ventanas con vidrio desde el año 1180 , se da por fuerza el descubrimiento de que las ventanas no sólo sirven para que entre el sol, sino también para que las miradas salgan por ahí hacia la calle, causándole a la gente una especie de nostalgia de la intemperie, y provocando una necesidad de salir a la calle, que empieza como necesidad de relaciones interdomiciliarias. Se instituye entonces la modalidad de las invitaciones a las casas, y puesto que la cocina es el centro, aparecen las comidas y cenas de invitados. La invitación es una forma de mostrarle al mundo la casa propia, con estilos, ideas y sentimientos, cuyo ostentoso resumen puede ser la imagen de Luis XIV atendiendo los asuntos de Estado desde su cama. En el recinto privado de la casa se crea una zona de intercambio público alrededor de la mesa del comedor, para la que se confeccionan formas de expresión especiales, arreglos, puestas de mesa, vajillas, tipos de menú, etc. Ciertamente para estas fechas la gastronomía empieza a mejorar, aunque lentamente, pero cuando menos ya no metían los cisnes vivos al horno, con plumas y todo; asimismo, se escriben algunos tratados de modales y costumbres referentes a la mesa, probablemente con carácter de urgentes.

\section{TERCER EMPLAZAMIENTO: LA CASA INAUGURA EL CAFE}

Si hay ricos y pobres, también hay casas completas como los palacios, y casas mínimas, casi accidentales, como las de cualquier hijo de vecino. Para la práctica de la invitación en las primeras se contruyen los salones, donde se suscitan las reuniones cortesanas y se celebran obras de teatro, conciertos de música y fiestas de bufones y cirqueros. En estas invitaciones, la intención es traer el mundo a la casa para mostrarle sus excelencias, por lo que la relación interdoméstica tiene características de espectáculo y entretenimiento, pero no exactamente intercambio recíproco de perspectivas; para los poderosos la reciprocidad tiene algo de incómodo. Prefieren una diversión candorosa, precisamente de cortesías, donde se acaricien los sentidos pero sin azuzar las neuronas, y así se hace curioso que desde su mismo inicio se considere a los salones como propios de mujeres, de lo femenino, con lo que se da principio a la separación social entre el hombre y la mujer, entre la racionalidad y al afectividad, y entre lo público y lo privado, de donde resulta la ya gastada ecuación: mujer, sentimental, en 
su casa. De todas maneras, al momento de abrir la puerta para que entraran los invitados, el aire de la calle se coló a la fiesta, y de este modo el teatro, los conciertos y las fiestas se volvieron eventos públicos, y los salones se convirtieron en teatros.

En las casas mínimas, por su parte, las invitaciones que se celebraban en la sala-cocina-comedor tenían de inicio la vocación de sacar la casa al mundo, y fundar allá fuera un intercambio de perspectivas domésticas, lo que implica crear un espacio comunicativo inédito, que no sea ni casa ni calle, sino otro, semiprivado y/o semipúblico, entre cuatro paredes pero con las puertas abiertas. $\mathrm{Ni}$ casa ni calle, por lo que se la llamó «casa pública» («Pub» significa Public House), que comprende, sobre todo los cafés, pero más tarde bares, restaurantes y todo aquel lugar que abra sus puertas para que la gente vaya a sentarse y se ponga a platicar, con el pretexto de un café o lo que sea. No deja de ser interesante que este nuevo espacio se funde alrededor de la estufa, del mismo aparato que hacía la casa, y con la gente en las mismas circunstancias de no tener nada especial que hacer; ciertamente el café es el hogar público. Los cafés se inauguran a partir de la ya difundida costumbre de tomar café, té y chocolate; florecen entre 1680 y 1730 , y para principios del siglo XVIII, solamente en Londres, había más de tres mil (5). Estalla la sociedad de las cafeterías. La razón por la cual parece necesario un espacio diferente al de la calle, es que la ciudad ya se ha vuelto demasiado grande, y entre mercantilismo e inmigración, demasiado poblada de desconocidos y extraños, por lo que se dificulta el establecimiento de una conversación más allá de las fórmulas de saludo y de trabajo.

La conversación que se suscita en los cafés se basa en una comunicación libre y animada sobre temas de interés común, y tocan por fuerza las cuestiones políticas del gobierno y la ciudad. Hablar de política es siempre controvertido, y de hecho en los cafés se inaugura el debate, la polémica, la discusión, como modo específico de comunicación, donde fluyen lạs ideas, ocurrencias, críticas, utopías, proyectos, soluciones. Lo que se pone en el centro del debate es en rigor la cuestión de la sociedad civil, y ya por eso, es en los cafés donde habita la sociedad civil. No es de extrañar que la gente se pasara más tiempo en el café que en su trabajo: los verdaderos acontecimientos políticos se daban ahí, y no en los gobiernos, como lo muestra el hecho de que los periódicos, en el sentido actual de la palabra, surgen no sólo en ese momento, sino también concretamente en ese lugar: su tirada equivale casi a un periódico por cada café; The Tatler tiraba cuatro mil ejemplares, y entonces parece lógico que los dueños de los cafés soliciten en 1729 el monopolio de los periódicos; después de todo, ahí eran leídos en voz alta para ser discutidos por todos y, en buena medida, ahí eran escritos. En efecto, la gente se reunía en los cafés para conocer las noticias, comentarlas, discutirlas, decidirlas, y en su caso, contestarlas por medio de cartas a la redacción. Hay continuidad entre palabra escrita y hablada, porque ambas son parte de la misma conversación, en la que cabían, por lo demás, hasta relaciones bancarias y de seguros; el banco Lloyd's de Inglaterra se funda en un café. No es raro que a los ojos de los gobernantes los cafés fueran lugar de agitación política, de la misma manera que para todo gobierno autárquico la sociedad civil es subversiva. Los cafés eran considerados como «penny universities», y los grupos que ahí se reunían se ponían nombres como «el pequeño senado». Ciertamente, el hogar público es el parlamento privado, donde se contruye la opinión pública como espíritu válido de la sociedad civil. Para fines del siglo XVIII, los parlamentos oficiales tuvieron que aceptar como correcta la 
voz de la opinión pública; y como en el ágora griega, en los cafés se hace la democracia, por cierto que reproduciendo hasta sus defectos, puesto que la sociedad de las cafeterías tampoco era para todos: si los griegos excluyeron a los esclavos, los dieciochescos a las mujeres: el café y el alcohol, la democracia y el conocimiento eran sólo para hombres (6).

La comunicación, aparte del lugar y el tema,.también es un estímulo y una regla de comunicación. Así, la conversación de los cafés y tabernas se basa en el acuerdo general de la igualdad de rangos; el café es un lugar de iguales, y las diferencias de la calle, el trabajo, el status y el dinero no tienen validez alguna; todos tienen el mismo derecho a la palabra y la misma obligación de escuchar a quien se sentara junto, porque las mesas eran compartidas por las extracciones más disímbolas. Puesto que se suspendían las diferencias, nadie era experto ni especialista en nada, o más bien, todos eran especialistas en todo, de manera que cualquiera podía hablar sobre demografía o literatura, sobre la sólida base de la igualdad conversacional. Por esta razón, se ponen en práctica en los cafés las reglas inviolables del tacto y la tolerancia, de la urbanidad en el mejor sentido de la palabra, de oír con atención al otro a condición de que el otro lo oiga a uno, de poder rebatir sin susceptibilidades, porque existe la prohibición de tocar cuestiones personales, y mucho menos ser utilizadas como argumento. Plessner define a la vida del café como la «esfera de la validez del tacto» donde impera la razón del mejor argumento, lo que permite, además de un diálogo fluido y enriquecedor, ilustrativo, percatarse también de la importancia de los convencionalismos sociales, cuando éstos son significativos.

El espacio de los cafés coincide con el de los teatros y otros entretenimientos; la diferencia es que los primeros usan la conversación y los segundos usan la actuación o representación. En los teatros los estilos y reglas aparecen en la forma de moda, arquitectura, estilos artísticos, etc. La teatralidad generalizada del tiempo de los cafés es óptimamente lúdica, porque sabe que la cultura o se juega o se vuelve burocracia, y se expresa característicamente en el barroquismo, ese estilo «conscientemente exagerado, intencionadamente imponente, reconocidamente irreal», como dice Huizinga. Y de todo lo que es barroco, el vestido sobresale, y de todos los vestidos, el masculino; a partir de 1620 , que los hombres se dejan crecer el pelo, la estilización y exageración de las modas aumenta; cada vez más pelucas, moños, lazos, rubores, coloretes, lunares, polvos, hasta llegar a fines del siglo XVIII, que termina con la moda totalmente burlona, humorística, increible, de los «incroyables», vestidos de riguroso exceso, con nada que envidiar a los «punks» de dos fines de siglo más tarde, como si siempre hubiera alguien dispuesto a cumplir los mitos de fin de siglos. La vida era teatral, un espectáculo de masas. Cabe notar que las puertas abiertas tienen la cualidad de confundir el aire de los espacios contiguos, y por lo tanto, la vida de cafés y teatros tiende a continuarse en el espacio público; se pierde la línea divisoria entre puertas adentro y puertas afuera, y de hecho no hay grandes diferencias entre barra, mesa, mesero y cliente, como tampoco entre escenario, actor, butacas y público; ni desde ambos sitios hacia la calle. En efecto, la gente que entraba al teatro se vestía y se comportaba igual que los actores; el ya inmortalizado Garrick (que de paso, era actor dramático y no cómico, como pregona Juan de Dios Peza) usó su ropa de diario para interpretar Otelo. $Y$ los actores aplaudían, contestaban, interrumpían sus diálogos, y los repetían en abierta interacción con el público, de donde se concluye que el actual teatro de revista tiene una memoria perfectamente localizable. En todo caso, así como 
el café es el teatro de las ideas y la razón, el teatro es el café de las imágenes y los afectos (7).

\section{CUARTO EMPLAZAMIENTO: EL CAFE ASCIENDE AL PARLAMENTO}

Una vez echada a andar la sociedad civil, la parte más asustadiza del café prefiere la paz de las jerarquías sociales y funda los clubs de caballeros, que son lugares semipúblicos, pero sobre todo semiprivados, donde se puede estar sin los contratiempos de ser iguales, ni siquiera de hablar, y donde por lo tanto no contaba la fuerza de los argumentos sino la fuerza de las credenciales y los apellidos; la intrascendencia civil de estos clubs es inversamente proporcional a su aceptación y evolución hasta la actualidad, en la forma de clubs deportivos, fraccionamientos para pocos, bares y discotecas por acciones, que se construyen para públicos privados que pretenden ser exclusivos, es decir, excluir: privado significa privar a los demás.

Pero la parte más animosa de los cafés, aquella que efectivamente construyó la Ilustración y armó una opinión pública válida y legitimadora, ascendió al parlamento, o sea, a la capacidad de decidir efectivamente sobre las cuestiones prácticas de la sociedad, y puso su conocimiento humanístico y científico al servicio del gobierno. Es cierto que el parlamentarismo es mucho más viejo; por ejemplo, el parlamento inglés se divide en dos cámaras desde 1332, desde el año que empieza la peste negra, pero lo que importa es que sólo hasta el año en que se termina la primera edición de la Enciclopedia Británica, hasta 1771, los debates de dicho parlamento obtienen el derecho a hacerse públicos, a formar parte de la coversación colectiva: dicho en este contexto, el parlamento deja de ser «casa» para volverse «café». El parlamento no debe tomarse en su acepción legislativa, históricamente sujeta a voluntades domésticas de poderosos, sino en su acepción parlante, o sea, dialógica, civilizada, parloteante y civil que se obtiene a partir de los cafés: el parlamento como café público en correspondencia con el café como parlamento privado, y no en menor medida, según se ha visto, como teatro, con sus actuaciones, altisonancias y diversiones.

Pero casi desde el principio, las virtudes del.café se transmutan en los derechos del parlamento, porque, por definición, si cambia el espacio, la comunicación es otra. El café alcanzó su nivel de incompetencia en el parlamento. En efecto, las ideas que se produjeron en los cafés, por ejemplo, la fe en la ciencia y la técnica como portadoras de civilización, hicieron suponer que el parlamento debería ser un lugar donde reinara la racionalidad ordenada, la verdad científica, la aplicación tecnológica, la utilidad cuantificable, la eficiencia productiva, es decir, los valores recién adquiridos de la sociedad industrial: la pretensión de hacer una fábrica de decisiones. Lo primero que sucede es que un parlamento así no puede ser un lugar para la gente, sino, por el contrario, un lugar para expertos, técnicos, especialistas, porque son ellos los que poseen el típo de verdad puesto de moda (8). Cuando hay expertos, la comunicación se acaba y empieza la información, porque ya no tiene la razón la persuasión volátil, sino los datos duros, y de hecho, en el mismo parlamento deja de discutirse y empieza a votarse, puesto que el número de manos levantadas es un dato más sólido que la calidad de los argumentos (9); la contabilidad de la razón. La institución de los expertos basados en el manejo de información es exactamente lo opuesto al principio de inexperiencia consensual que obligaba en el café; de hecho, la 
separación entre uno y otro se consuma en el momento en que se empieza a pagarles un salario a los parlamentarios, porque ello implica el reconocimiento de que se trata de un trabajo especializado y engorroso, mientras que nadie pudo jamás cobrar por platicar en un café: hacer política era un gozo civil, ahora es una profesión.

De esta manera el parlamento se constituye en el lugar de la ruptura de las igualdades, y como tiene poder para ello, la hace valer: diseña una tecnología capaz de aplicarse al gobierno, técnicamente llamada "administración», cuyos mecanismos configuran la máquina burocrática de gobernar. El gobierno como burocracia tiene el objetivo técnico de organizar la sociedad y administrar los recursos, pero, este objetivo, desde le punto de vista de la comunicación civil, es en realidad otro: indicar la separación entre administración y gente, dejar claro que no son iguales; el diseño de ventanillas, filas, escritorios, formularios, archivos, etc., que configuran la arquitectura y decoración de la administración pública, son objetos que se colocan entre el funcionario y el ciudadano, para mostrar físicamente que están situados en lugares distintos, y las mismas atribuciones del funcionario, tales como saber el nombre del otro y hacerle preguntas pero no viceversa, fijar los horarios, cerrar ventanillas o conocer el reglamento interno pero no viceversa, dejan claro que el administrador es el experto y el usuario un tonto importunante. En general, la labor de un experto consiste en ocultar información, como lo hacen los magos, o los médicos que explican las dolencias con tecnicismos para que el paciente no se entere y siga consultándolo.

En fin, el parlamento tiene ciertamente las características de un nuevo ámbito comunicativo de la colectividad, pero es el lugar donde el aire de la calle da vuelta y se regresa, puesto que allí ya no hay gente, sino expertos, y ya no hay comunicación entre ellos, sino información, por lo que se trata principalmente de un espacio informacional extrapúblico, o espacio informático, para decirlo más al día con los avances tecnológicos. Como puede verse, es más bien descarnado, o como dicen los que tienen que hacer trámites, deshumanizado.

\section{REEMPLAZAMIENTOS Y DESPLAZAMIENTOS: LA ADMINISTRACION SE METE HASTA LA COCINA}

Desde la máquina de administrar, situada por arriba de la calle y de la vida pública, se procede a organizar la vida según los criterios de la sociedad industrial, en un abc que empieza por (a) la calle. Esta se planea para el tránsito, para el transporte de la mayor carga posible (persona, animal o cosa) por la mayor distancia posible en el menor tiempo posible, sin obstrucciones ni distracciones. París es atravesada y cortada por bulevares, en 1860 (10), y desde 1850 el transporte masivo se ha intensificado; sólo en 1866 se transportaron 107 millones de pasajeros. Londres inicia la construcción del metro en 1863, aunque en el mismo año se da tiempo para tratar de establecer la diferencia entre el fútbol y el rugby, que por entonces no era nada clara; el metro empieza a funcionar en 1890 , año en que también se establece una línea telefónica con París, y quizá lo primero que se platicaron fue de sus respectivos pánicos financieros, que tuvieron a bien estallar en el mismo año y en las dos ciudades. A partir de 1840, los periódicos son por fin de verdadera difusión masiva, con grandes tiradas, mientras que el correo se multiplica debido a que todo el mundo envía facturas. Lo que realmente se está inventando son las prisas, las caras ocupadas y los pa- 
sos diligentes, por lo que los relojes de bolsillo empiezan a producirse en serie también desde 1840, y las cortesías se emplean ahora para no estorbar ni ser molestado, para no quitar tiempo, y asimismo se emplea el paño negro para confeccionar una moda seria y práctica como corresponde a quien no pierde el tiempo en pasatiempos inútiles. La racionalidad ocupa la calle, y la afectividad para su casa; el hombre ocupa la calle, y la mujer para su casa, donde puede seguir arreglándose con la calma y la irracionalidad que el siglo le atribuye.

En 1838, en Francia, se prohíben las discusiones públicas de (b) café entre los trabajadores, bajo el pretexto de que bebían demasiado en las tabernas, aunque la verdad era que practicaban el subversivo arte de la conversación. Los ingleses, más flemáticos para su despotismo, no prohíben, pero igual consideran una falta de decoro beber, e incluso estar, en lugares públicos, así que desde 1830 disminuyen las tabernas y aumentan las vinaterías, donde uno compra su botella y se la va a beber respetablemente en privado. Las casas públicas se han vuelto «casas públicas», y también las mujeres que persisten en andar por la calle (11). Por otra parte, aparece en 1852 también la primera tienda que vende mercancía a precios fijos: el «Bon Marché», evitando el dilatado regateo, porque ya patentada la máquina Singer desde el año anterior, hasta la alta costura se hace en serie, y es por tanto indispensable vender más y platicar menos. La función del regateo se sustituye por la publicidad, y la primera agencia de publicidad surge en 1855, en Alemania, contra toda la ética de los viejos comerciantes, que consideraban falto de moral anunciar sus productos. Como puede observarse, esta secuencia de reemplazamientos y desplazamientos de espacios es lo que de otra manera se puede llamar el ascenso de las clases medias. Para entonces, en el teatro ya sólo se aplaude con recato, pero no se grita ni se llora ni se insulta, ni se siente, como antes, porque eso de sentir en público ya se ha vuelto de mal gusto, estorboso e ineficiente: la teatralidad también se va para su casa. No es de extrañar que por este tiempo la lectura comience a hacerse en silencio, cosa que antes no se usaba ni para leer a solas; de hecho, la gran tirada de los periódicos equivale paradójicamente al aislamiento de la comunicacíon: se requieren tantos periódicos y con tantas secciones (desde finanzas hasta nota roja) porque cada quien lo lee para sí mismo, tan calladamente que ni el de al lado lo pueda oír. Lo que se está edificando es el aislamiento; la apariencia de progreso que tiene se debe a que se construye monumentalmente.

El diseño y función del espacio doméstico no escapan a los encantos del progreso científico aplicado al modo de vida: los avances en materia de salud e higiene logran convencer de que la planificación de la vivienda debe hacerse técnicamente, basándose en variables tales como iluminación, ventilación y separación de funciones (12), es decir, no estar todos juntos haciendo de todo en un cuarto cerrado, sino cada quien con sus cosas en lugares especiales de (c) la casa: ni dormir donde se come ni platicar donde se cocina. Puesto que tal orden es una idea pública que se mete en un espacio privado, la separación de funciones concuerda con la separación entre actividades que pueden ser mostradas públicamente, y aquellas que no mucho o de plano no; es decir, entre lo que es de buen decoro y lo que es indecoroso: lo ordenado y adornado se considera público; lo sentimental o fisiológico, privado. Lo orgánico y lo emocional se equiparan: a los dos se les llama «la carne»; aquello que las normas de urbanidad no pueden transmutar del todo, como lavarse o estar enfermo, pasa a formar parte de lo privado. Aquello que queda a medio camino entre lo fisiológico y lo ornamental, como la comida, se pone en el sitio intermedio 
que corresponde al comedor y la cocina, destinado a atender a «los amigos de la casa». Paulatinamente la casa se va subdividiendo en su interior, como si le crecieran lugares por dentro: la sala de estar se convierte en sala de visitas y en el lugar más cercano a la calle, con decoración de buen gusto público; el comedor se formaliza, la cocina se funcionaliza y quienes entran a ella tienen que oír una frase de disculpa por el desorden. La casa se va desdoblando hacia adentro para inaugurar sitios más privados dentro de la misma privacía: pisos, paredes, desniveles y puertas se multiplican, y lo más privado se pasa a una segunda planta donde queda la estancia familiar, en realidad reducida a un pasillo, porque ya se han erigido paredes para hacer recámaras, es decir, cuartos dentro de cuartos, casitas dentro de la casa, donde habitar; se instituye la extraña idea de las puertas interiores para separar a la misma gente de una casa, y puesto que las puertas son para cerrarse, la posible convivencia queda detrás de ellas, aunque no del todo, porque las recámaras todavía tienen puertas en su interior, que dan hacia los closets y guardarropas: puertas tras las puertas para guardar cosas no mostrables ni al cohabitante de cuarto, porque son de interés personal o, como dicen sus poseedores, de valor sentimental. Hacia afuera se vive como si lo de adentro no existiera.

En todo caso, es como si el espíritu colectivo, empujado desde el parlamento hacia afuera de la calle y fuera de los cafés, en la casa tampoco encontrara un lugar donde situarse, arrimándolo cada vez más hacia un rincón. A todo esto, cabe un paréntesis: el de la mujer, porque queda considerada por la sociedad como un lugar más de la casa, como el paréntesis ubicado más o menos entre la recámara y el guardarropa, para el cual se construye un muro de tela y una puerta de botones, que la hace inmostrable e inaccesible, como debe ser todo lo que es privado, afectivo e irracional. Para 1840, el traje femenino ya tenía botones hasta el cuello y faldas hasta el tobillo, como primer paso; como segundo, surge la moda de los miriñaques, que son esas estructuras de metal que se usaban bajo el vestido, y que estaban hechas con la misma ingeniería y la misma estética que las estructuras de hierro que por las mismas fechas (c. 1850) se empezaron a utilizar para construir puentes, mercados y estaciones de ferrocarril: un ejemplo sintomático de esta arquitectura es el nuevo local del Bon Marché, construido por Eiffel y Boileau en 1876: un miriñaque habitable. El miriñaque del traje femenino sirve para distorsionar la apariencia del cuerpo, como dice Sennett, de manera que no hubiera relación entre un cuerpo vestido y uno desvestido, puesto que la mujer no sólo no debía ser vista, sino tampoco imagina$\mathrm{da}$, al grado de considerarse inconveniente que la gente que entrara a una casa le viera las patas a la mesa o al piano, porque por asociación podía imaginarse las piernas de su dueña; así que se les cubría (13).

\section{QUINTO EMPLAZAMIENTO. ULTIMO SITIO DE REUNION: EL INDIVIDUO}

La organización técnica de la sociedad industrial parece querer sacar de lo público y empujar hacia lo privado a los espacios comunicativos de la colectividad, cosa que no puede hacer porque éstos se preservan como memoria colectiva, pero lo que sí logra es crear uno nuevo: el cuerpo como espacio íntimo individual, como un lugar todavía más allá de las recámaras y los closets, tras las puertas de la piel. 
Aunque desde 1596, Harrington, no aquel James que escribió y discutió en los cafés su utopía Océana, sino John, inventó el Water Closet, éste también resultó utopía porque, es sólo hasta 1778, cuando John Bramah construye otro que, gracias a los avances de la revolución industrial en materia de cañerías, el W.C. tiene éxito. Lo que estrictamente se construyó fue un nuevo cuarto de la casa, y ciertamente todas las definiciones de diccionario a él se refieren: «water closet» $\mathrm{o}$ «WC cuada de los intestinos puede ser desaguada por tubería mediante agua proveniente de una cisterna»; en efecto, se trata de un cuarto de agua, porque «closet» es un «cuarto», y aunque en su uso actual y norteamericano sea un «cuarto pequeño para guardar cosas», en su uso antiguo e inglés era un «cuarto pequeño para entrevistas privadas». Ahora, en castellano en desuso, el «retrete» es un "cuar to pequeño en la casa, destinado para retirarse», y por ciertas razones, se instaló allí el aparatito inodoro; «excusado», por su parte, fue un adjetivo que significa «retirado o separado del uso común», y que califica al cuarto: cuarto excusado. Así, excusado y privado vienen a ser sinónimos, lo cual serviría para hablar del capital excusado. Y efectivamente, el baño es un lugar de la casa, el último, donde la gente puede entrar intempestivamente, bajo el común acuerdo de que lo que haga allí dentro es cosa suya, y nadie debe preguntar y todos pueden no contestar qué estaba haciendo. Por lo tanto, excepto para los niños, que no se les ha otorgado el derecho a la privacía, el baño puede utilizarse, como de hecho se utiliza, para toda clase de expresiones igualmente poco sociables como llorar, reflexionar, ensayar gestos, sentirse contento con criterios distintos a los buenos modales, leer, recitar bajito, distraerse, tardarse, estar ocioso, etcétera; un poco eso que se llama «ser uno mismo», que aunque no exista, se siente bien.

Bajo el argumento científico de que el baño es un lugar sano y saludable, la arquitectura utilitarista cambia de profesión: ya no está al servicio del «hogar» como hasta entonces, sino al servicio del «cuerpo», y para éste construye, y con ello dibuja el croquis del último sitio de reunión de la sociedad. No tiene, después de todo, nada de extraño que uno de los primeros objetos que fueron introducidos al baño sean los espejos, porque, dado que la gente se mete al baño para estar consigo misma, puesto que entra a verse a sí misma, se hace natural que lo haga cara-a-cara. Mientras que uno conoce sus propios pensamientos mediante la reflexión, los espejos son la única forma de conocer los propios gestos, y de dirigirlos a uno mismo: así como uno puede peinarse, igual puede sonreírse, gustarse; el espejo es la forma de reflexión del sentimiento, como bien saben los actores, que estudian sus expresiones frente a él. La reflexión del pensamiento se llama reflexión porque hace con palabras lo mismo que el espejo hace con imágenes: lo refleja a uno mismo.

El baño es el umbral del individuo, ese nuevo espacio comunicativo que se abre frente al espejo. El cuerpo es un espacio en el mismo grado que los otros espacios, como puede verse por el hecho de que se hable cotidianamente del «interior» o de «aquí adentro» para referirse a los pensamientos y sentimientos que habitan el propio cuerpo. El espacio individual es en realidad un poquito más grande que el cuerpo, como si tuviera un halo del tamaño de la apariencia vestimentaria, los movimientos del cuerpo, los tonos de voz, los estilo personales y las gesticulaciones, en franca continuidad con el espacio comunicativo contiguo; también el individuo continúa hacia adentro, con una departamentalización más o menos isotópica, que tiene igualmente sus lugares públicos y privados. 
En su parte pública accesible se ubican las ideas e imaginaciones colectivamente admitidas como racionales, razonables, civilizadas, agradables, publicables; lo público individual ha recibido el nombre de lo consciente, mientras que su parte más privada, alejada, cerrada, excusada finalmente, recibe el nombre de lo inconsciente, que hace pensar que hay un lugar dentro del cuerpo donde nosotros somos visitas de nosotros mismos, forasteros de nuestro cuerpo; en rigor es correcto, porque quien lo ha inventado, diseñado, amueblado y habitado es la colectividad, de la misma manera que lo ha hecho con los demás espacios. El sí mismo es «algo que es está pensando dentro de mí», como escribió Onetti.

Es justamente cuando el espíritu colectivo empieza a ser empujado hacia los rincones de la intimidad, en los finales del siglo XVIII, que aparecen la novela sentimental, el género epistolar «de corazón a corazón», el diario íntimo, el romanticismo y la psicología: todos ellos pretenden ser intento de expresión y conocimiento de lo subjetivo, aunque en realidad están inventando esa subjetividad que luego van a expresar y conocer. Se inicia la moda de la expresión o represión individual, según se vea la feria de la vida, pero, en todo caso, debido a que cuaja como espacio comunicativo, la sociedad en su conjunto empieza a ser vista a través de los ojos del individuo, y ahora los acontecimientos sociales son los individuos; los grandes individuos son los grandes acontecimientos de la sociedad, aquellos que han salido de baño hechos «toda una personalidad», y que al hacer su presentación en los otros espacios, sobre todo el teatro, la calle y el parlamento, crean el mito de la fama e instituyen el «star system», cuya primera superestrella fue Paganini, un húngaro violinista que a decir de sus contemporáneos no era exactamente un gran músico, pero su presencia era impactante, máxime cuando le reventaba dos o tres cuerdas al violín y seguía tocando: en realidad era un brillante ejecutante de sí mismo, un excelente actor de su personalidad. El nombre de la última superestrella (y en medio queda Lenin, Einstein o Picasso, que ya pertenecen al panteón de la sociedad del espectáculo de la personalidad) está a discusión, pero puede proponerse a John Lennon, que sintetizó en su imagen los sueños de una generación, incluyendo la forma en que terminaron.

\section{SINOPSIS}

Todo lo que se ha tratado de argumentar es muy poco, concretamente, que el espíritu colectivo piensa y siente mediante espacios, por lo que éstos deben entenderse como verídicas personas colectivas, que se mueven, no entre lo consciente y lo inconsciente ni entre lo racional y lo pasional, ni entre lo social y lo individual, sino entre lo público y lo privado. Esto cabe en un esquema.

Este esquema se puede leer de la siguiente manera: la colectividad, que abarca todo el esquema, empieza pensando y sintiendo con la calle: la calle inventa la casa; la casa construye el café, el café crea el parlamento: el parlamento se revierte y al final la colectividad crea al individuo. Este proceso de creaciones es un juego entre los público y lo privado, entre hablar y callar, juntar y aislar, mostrar y ocultar, pero lo que se puede notar al término de la historia es que ya no hay demarcación clara entre lo público y lo privado, sino que ambos están en todas partes, y todas partes tienen sus decretos y sus secretos: cada espacio tiene su publicidad y su privacidad. La sala es lo público de la casa, y la recámara, lo privado, de la misma manera que los espacios generales pueden ser públi- 


\section{3}

\begin{tabular}{|c|c|c|c|c|c|}
\hline $\begin{array}{l}\text { ESPACIO } \\
\text { EXTRAPUBLICO } \\
\text { INFORMACIONAL }\end{array}$ & & & $\begin{array}{l}\text { parla- } \\
\text { mento }\end{array}$ & $\begin{array}{l}\text { adminis- } \\
\text { tración - } \\
\text { pública }\end{array}$ & $\rightarrow$ \\
\hline $\begin{array}{l}\text { ESPACIO } \\
\text { PUBLICO } \\
\text { URBANO }\end{array}$ & $\begin{array}{l}\text { plaza } \\
\text { pública }\end{array}$ & - calle & & 1 & \\
\hline $\begin{array}{l}\text { ESPACIO } \\
\text { SEMIPUBLICO } \\
\text { SEMIPRIVADO }\end{array}$ & & & $\begin{array}{l}\text { café } \\
\text { teatro }\end{array}$ & $V$ & \\
\hline $\begin{array}{l}\text { ESPACIO } \\
\text { PRIVADO } \\
\text { DOMESTICO }\end{array}$ & & casa. & & 1 & \\
\hline $\begin{array}{l}\text { ESPACIO } \\
\text { INTIMO } \\
\text { INDIVIDUAL }\end{array}$ & & & & $\begin{array}{l}\text { cuerpo } \\
\text { (interio- } \\
\text { ridad) }\end{array}$ & $\rightarrow$ \\
\hline $\mathrm{m}$ & & $X$ & XVII & III, X & $x x \rightarrow$ \\
\hline
\end{tabular}

cos o privados con respecto a otros, como el café, que es casa pública o departamento privado, según se vea. El significado de «hacer algo en público» depende del espacio en que se esté hablando.

Esto no es historia, porque los datos son meros ejemplos del argumento (14), sobre todo porque se trata del presente: en efecto, el espíritu colectivo piensa, siente y se mueve actualmente, con las construcciones y distribuciones de los espacios creados poco a poco (15). De la misma manera que hoy pensamos con lo que recordamos y que los recuerdos están depositados en las cosas que traen recuerdos, así la vida contemporánea está hecha de memoria; las ideas, estilos, humores que se usan en la actualidad nacen en algún emplazamiento de la memoria colectiva. La gente, en general, está hecha de todos estos espacios, por lo que se puede entender que alguien sea estrictamente solemne en la ropa, los modales, las opiniones y el lenguaje durante una reunión de trabajo, y estrictamente ridículo, juguetón, ingenuo y hogareño durante una reunión familiar, y que ambos comportamientos sean vistos desde una tercera perspectiva como estrictamene patéticos. Una misma gente es, con toda honestidad, cuatro o cinco personas distintas durante el día: se puede creer en el sexo y la salud, en la sopa caliente, en la tolerancia y el iluminismo, en el pueblo y la comunidad, y en el organigrama de la oficina, según el espacio vaya cambiando. Quienes piensan son los espacios y si, por ejemplo, uno deja de leer y se levanta para ir a hacer café, podrá advertir en el trayecto que va cambiando entre el pensamiento de la colectividad. 


\section{Notas}

(1) En efecto, el Agora Griega era un lugar vacío, que no contenía ningún templo, ni altar, edificio público o habitación, puesto que estaba diseñado específicamente para ser ocupado por gente. Asimismo, las viviendas griegas eran sumamente frugales, y quien tuviese una casa demasiado grande era expulsado de la ciudad (cfr. Giedion, 1952). De la alta preminencia de la vida pública se pueden entender ciertas excentricidades, como, por ejemplo, el hecho de que los retóricos y sofistas fueran los vagabundos (cfr. Huizinga, 1937), puesto que no salían del espacio público; o que Protágoras, además de fundar la retórica, tenga la reputación de haber inventado una prenda acojinada para facilitar la carga de cosas («porter's pad»; cfr. Billing, 1987, p. 41), es decir, una forma de cargar por las calles públicas sus adminículos de vida privada. También el mito de Diógenes, viviendo dentro de un barril, es perfectamente razonable dentro del marco de la vida pública griega.

(2) Por lo demás, el trazado laberíntico de las ciudades medievales tenía también una función de sobrevivencia, puesto que servía para que en ellas se perdieran los invasores que lograban cruzar la muralla, de manera que no pudieran llegar fácilmente al centro.

(3) Giedion (1940, p. 33 ss.) encuentra en la sorprendente creación de la perspectiva lineal el comienzo de la modernidad; la perspectiva es una obra colectiva, porque efectivamente la colectividad lo crea todo, hasta la individualidad, aunque sus primeras expresiones concretas pueden verse en el fresco «La Trinidad» de Masaccio (discípulo de Brunelleschi, y es probable que éste haya pintado la perspectiva de ese fresco), y en la capilla de San Andrés, en Mantua, de Alberti, a quien el fresco de Masaccio sirvió como modelo. La idea del alineamiento de las calles para el tránsito del poder mercantil es de Churchill (1945), y se resume en esta frase suya: «Los desfiles y el poder no son sutiles: necesitan grandes espacios, obviedad simétrica y simpleza, porque la comprensión que les corresponde es burda» (p. 12-13). Respecto a los museos, véase a Bell (1987): en los museos «toda clase de objetos creados por la cultura, y arrancados de sus contextos tradicionales, son exhibidos en un nuevo contexto de sincretismo: el de una historia revueltan (p. 28). Por otra parte, Werner Sombart le atribuye los libros de contabilidad a un tal Luca Pacioli, y con ellos se instituye la cuantificación, según la cual las cosas se ven como dinero, y ya no como cosas concretas; siempre es agradable citar a Churchill: «la Iglesia perdió su tiempo peleándose con Galileo, porque la Ciudad de Dios no cayó por la ley de la gravedad, sino por la regla de los contadores» (1945, p. 18). Por último, la cuestión de los Turcos corresponde al humor involuntario del sistema de enseñanza de la educación primaria.

(4) Así como el poder y el gobierno, también la producción y el comercio pueden considerarse como cuestiones caseras de relaciones entre moradores particulares. Así, por ejemplo, los periódicos y correos de los siglos XV y XVI funcionan explícitamente como intercambio de información entre los comerciantes, cuyo negocio dependía a menudo de ciertas noticias. Sin embargo, el llamado de la calle medieval, como memoria colectiva viva, sigue vigente; así se explica que dichos periódicos tiendan a incluir cuestiones de interés general y sabiduría pública, como, por ejemplo, historias de «lluvias de sangre y fuego, de conversiones de judíos, de quemas de brujas y condenas diabólicas, de juicios divinos y resurrección de muertos» (Habermas, 1962, p. 279). Por lo demás, estas noticias estaban escritas en verso, porque estaban redactadas para ser leídas en voz alta ante una audiencia, de suerte que no cabe hablar de analfabetismo, aunque los oyentes no supieran leer, sino de una especie de alfabetismo oral, como método de comunicación social, que sólo trató de replegarse hasta el siglo XIX, que es cuando ya se puede hablar realmente de analfabetismo: la oralidad continúa como forma de comunicación propia de los espacios comunicativos de la calle y de la casa, no obstante hasta nuestros días; la Caperucita Roja es un buen ejemplo, porque hay variaciones enormes entre la narración original, donde la Caperucita muere; en Perrault, que transcribe sus Cuentos del Tiempo Pasado en 1697, donde el Lobo invita a la Caperucita a la cama; y en el cuento actual, con final feliz: lo que se puede observar es que, a pesar de Perrault, el cuento no ha podido ser sacado de la tradición oral, y como dice Margit Frenk, en toda literatura oral las versiones cambian y se acomodan según sea necesario, y así el texto se mantiene vivo. Por otra parte, muchas de aquellas noticias en verso se han preservado hasta la actualidad en la forma de rimas infantiles, del estilo de "Doña Blanca», sin afirmar que éste sea un caso concreto.

(5) J. M. Pérez Gay da 1687 como el año en que un oriental abre la primera casa de café en Europa. Ahora bien, la ausencia de tradición del café en los países latinoamericanos, en general, puede entenderse por las prohibiciones virreinales sobre la existencia de lugares donde los habitantes novohispanos se reunieron a platicar, comer o beber sin vigilancia; así, los lugares para beber se establecían en la vía pública, en el entendido de que al encontrarse en público se comportarían con mayor decencia a la vez que podrían ser vigilados con mayor eficacia. Los españoles de todas maneras bebían en sus casas, y de todas maneras no pudieron evitar las independencias. Lo que sí hubo, en cambio, fueron entretenimientos públicos como los teatros, las procesiones, los toros y el frontón (cfr. Viqueira Albán, 1987).

(6) Del año 1674 es ya el panfleto «Petición de las Mujeres contra el Café, presentado a la Consideración Pública, debido a los Grandes Inconvenientes que el Uso Excesivo de este Resecante, Debilitante Licor ocasiona a las Actividades propias del Sexo (The Woman's Petition against Coffee, representing to Public Consideration of the Grand Inconveniences according to their Sex from the excesive use of that Drying, Enfeebling Liquor) (Habermas, 1962, p. 283). 
(7) Desde el punto de vista del gobierno y de los reyes, todo esto, el café y el teatro, era riesgoso: al poder siempre le resulta preferible el orden a la comunicación. Y sin embargo, la arquitectura oficial realiza un gesto involuntario, en el siglo XVII en París y Londres: construye plazas y espacios abiertos; aunque el fin reconocido era el embellecimiento cortesano de la ciudad, su significado real aparecería no sólo en la Revolución Fracesa, sino en los movimientos de masas del siglo siguiente. En el otro extremo, la casa también realiza un gesto involuntario de utilización pública posterior: puesto que a nadie le interesaba ya lo que sucedía tras sus puertas cerradas, el estilo interior se hace negligente, como lo ejemplifica la ropa negligée, cómoda y desenfadada, de donde salen, además de los incongruentes negligés de hoy, la moda cuasi negligée de miradas lánguidas, pelo revuelto y ropa distraída que caracterizó al romanticismo, y que ahora caracteriza a todos los movimientos culturales a partir de la posguerra. Con lo negligé, el espacio privado de la casa empieza su proceso de desentendimiento de lo público, que va a marcar la pauta de los siglos XIX y XX.

Datos respecto a los cambios en la traza urbana, pueden encontrarse en la historia de Giedion (1940), donde el diseño de jardines, empezando con los del Palacio de Versalles, juegan un importante papel. Respecto a otros datos, aquellos sobre las casas de café y su relación con los periódicos y revistas, así como con la vida política e intelectual, se pueden encontrar en la historia de la opinión pública de Habermas (1962), donde aparecen cosas como, por ejemplo, que en Inglaterra, el periódico The Tatler, de luminosa y fugaz existencia, se dirigía expresamente a «los prósperos ciudadanos que pasan más tiempo en las casas de café que en sus negocios» (p. 286), o que en el café Button, la correspondencia a los periódicos se colocaba en las fauces de un león esculpido, por lo que luego apareció una revista con el nombre El Rugido del León; es a través de la vida de los cafés que el público sustituye a la «humanidad» como protagonista de la sociedad, y su opinión, la pública, es admitida como legítima por el parlamento en 1792, unos veinte años después de que los cafés habían sido duramente criticados en ese lugar, por auspiciar la perversión intelectual de los buenos súbditos de Su Majestad. Datos respecto a las casas de café o casas de refrigerio y sus reglas de conversación, respecto al teatro y sus usos y costumbres, así como respecto a las modas, entre otros, pueden encontrarse en el libro de Sennett (1974) sobre el hombre público, donde se consignan anécdotas de la siguiente clase: «en Londres, los lunares se colocaban en el lado derecho o izquierdo del rostro y la ubicación dependía de que uno fuese liberal o conservador. Durante el reinado de Luis XV, los lunares se usaban para indicar el carácter del parisino: a un costado del ojo representaba la pasión; en el ceritro de la mejilla, la alegría; en la nariz, insolencia. Se suponía que una asesina debía usar lunares en los pechos» (p. 92-93). Y así sucesivamente, entre el uso cotidiano de antifaces, de pelucas con el modelo a escala de un barco entre olas de peinado, o de una altura que no permitía cruzar las puertas, entre el empleo de munecas vestidas como tal o cual aristócrata se había vestido alguna vez, que se exportaban para ser copiados, se llega hasta el punto máximo, en 1795 , de la apariencia negligée del cuerpo semidesnudo, mojando la ropa de muselina para que se transparentara el cuerpo, cuya consecuencia inmediata fue una epidemia de tuberculosis al primer invierno, o el corte de pelo «a la victime», o sea, a lo guillotinado, según se les cortaba a aquellos que iban a ser decapitados. De hecho, junto con las cabezas de la guillotina, también rodaron las pelucas, que según Huizinga, son uno de los elementos más significativos de los siglos XVII y XVIII, tanto más por su uso masculino; respecto a las modas y el Barroco, el Rococó y por último en Neoclasicismo, y su relación con el espíritu lúdico de la cultura, véase el Homo Ludens de Huizinga (1937).

(8) Una argumentación respecto a las diferencias entre la comunicación (denominada acción comunicativa, interacción simbólica o conocimiento práctico) o información (acción racional con respecto a fines, o trabajo) puede encontrarse inmejorablemente en Habermas (1968). Según él, la ciencia y la tecnología, gracias a su producción material a partir de la revolución industrial, se salen de su esfera adecuada que es la de la información, y se introducen irracionalmente a la esfera de la comunicación, donde no pueden pertenecer, por lo que se convierten en ideología; ideología se define aquí como «comunicación sistemáticamente distorsionada», y como tal es propia de la revolución industrial, e inexistente antes de ella.

(9) Según Tarde, la contabilización de la opinión es otra de las paradojas producidas por la generalización de la prensa como medio de información: la gente, al tener el periódico en su casa, ya no tiene que ir al café para enterarse de nada, de modo que se pierde el contacto personal, y con ello la necesidad de comprender el punto de vista del otro; el elemento afectivo del conocimiento social es amputado de los métodos de conocer, y con él se pierde también la comprensión misma: «la prensa periódica capacitó a los grupos primarios de individuos similares, para formar un agregado secundario mucho mayor, cuyas unidades estaban estrechamente ligadas sin necesidad de contacto personal. De esta situación surgieron diferencias importantes; entre otras, ésta: en los grupos primarios, la voz de sus miembros es ponderada - ponderantur - antes que cuantificada - numerantur -, mientras que en los grupos más grandes y secundarios, a los que se adhieren a ciegas individuos que no pueden verse entre sí, la voz sólo puede ser contabilizada, pero no sopesada. Así, la prensa coadyuvó inconcientemente a la creación de la fuerza del número, y a la reducción de la fuerza del carácter, si no es que de la inteligencia» $(1989$, p. 302).

(10) Uno de los objetivos sociales de la nueva urbanización del siglo XIX era, claramente, el control de las multitudes. El caso ejemplar es el de París y la urbanización emprendida por Georges Eugéne Haussmann, «a tono con la época industrial», como dice Giedion. Concretamente, 
los propósitos de Haussmann eran los siguientes: $1 .^{\circ}$, «aislar los grandes edificios, palacios y cuarteles, de manera que resultaran más agradables a la vista, y que permitieran un acceso más fácil en los días de celebración de actos, y que simplificaran la defensa en los momentos de revuelta»; 2..$^{\circ}$ «mejoramiento del estado de salud de la ciudad por medio de la destrucción sistemática de callejones infectos y otros focos de infección», y $3 .^{\circ}$, «asegurar la paz pública por medio de la creación de amplios bulevares, que no sólo permitieran la circulación del aire y de la luz, sino también el fácil acceso y movimiento de tropas. Con esta ingeniosa combinación, el destino del pueblo se verá mejorado, y su continua disposición hacia la revuelta disminuirá» (citado por Giedion, 1940, p. 668). Cabe aquí reconocer el irónico sentido del humor que tiene la historia, porque «boulevard» quiere decir «muralla» (bulwark). Ahora, todo junto puesto en una frase de Churchill (1945, p. 20): «París impuso el nuevo estilo de planeación. Napoleón III, un tonto y un déspota, vio que las multitudes no podrían ser controladas en la vieja ciudad. El Barón Haussmann, un déspota pero no un tonto, lo arregló, no sin beneficio propio."

(11) Así comienza la bohemia tradición de «los bajos fondos», como los llama y documenta González Rodríguez (1988): en efecto, con el ordenamiento de la sociedad industrial, un lado de la sociedad se oscurece; no se pierde, sino que sólo se traslada a sitios más privados de la colectividad, esperando el momento oportuno para reaparecer en público.

(12) En realidad, la aplicación técnica del conocimiento médico se formaliza en la arquitectura hasta los años de 1930, con el Funcionalismo (cfr. Gehl, 1980, p. 45), que construye la casa «orientada al sol, y no, como había sido previamente, orientada a la calle». Sin embargo, esta búsqueda de condiciones apropiadas para el cuerpo, como intentando escombrar un terreno que sirviera de sitio para el nuevo espacio comunicativo del individuo, aparece socialmente desde antes, desde el estilo habitacional del siglo XVIII: «En las mansiones privadas de las grandes ciudades han sido reducidos a su mínima expresión todos los espacios funcionales a la "casa completa": los amplios vestíbulos se han visto reducidos a un mísero zaguán, y por la profanada cocina sólo corretean doncellas y cocineras en lugar de la familia y el espíritu hogareño; pero es sobre todo notable que los patios se hayan convertido en rincones a menudo angostos, húmedos y malolientes. Si echamos un vistazo al interior de nuestras viviendas, encontramos que la "habitación familiar", esto es, la estancia común de marido, mujer y niños y servicio se ha hecho cada vez más pequeña, si no ha desaparecido del todo. En cambio, las habitaciones particulares de los diversos miembros de la familia han sido provistas cada vez más y con mayor propiedad. El aislamiento del miembro de la familia incluso en el interior de la casa pasa por distinguido» (Riehl, citado por Habermas, 1962, p. 82 ).

(13) Hay algo de trucado en las moralizaciones machistas de la época, en dos sentidos. Primero: la desfiguración del cuerpo femenino proporcionaba la idea de que bajo el vestido habitaba la forma misteriosa, oscura y desconocida de la pasión irracional, lo cual lo hacía un objeto más digno de escudriñar; en efecto, como argumenta Descamps (1979), la esencia de la ropa radica en mostrar más que en cubrir: mientras más oculta, más revela, porque marca exactamente los sitios del cuerpo que hay que atender (actualmente nadie está interesado en los tobillos de nadie, porque no se ocultan): la ropa sirve para dejar todo a la imaginación, que es más real que los hechos objetivos. Segundo: la pasión e irracionalidad que se guarda en el habitáculo de la mujer, es la del hombre; es el hombre quien la endosa sus privacidades para apartarlas de sí, para fingir en público que no las tiene, y para ir de vez en cuando a por ellas: la mujer queda socialmente considerada como el objeto más privado del hombre, pero no necesariamente como el más gozable, según preconiza la noción de la mujer como objeto sexual, sino probablemente como el más doloroso. Finalmente, debido a la gran cantidad de elementos que el racionalismo tecnócrata depositó en el lugar de la mujer, de este lugar surgen las mejores alternativas de la cultura del siglo XX; concretamente, la posibilidad de una sociedad más sensible y razonable, menos poderosa y violenta, está contenida de antemano en los estereotipos de lo que el sentido común considera como característicamente femenino. En el caso de las ciencas sociales y la filosofía, puede observarse actualmente una especie de «feminización del método», que ya no consiste en la dureza de los datos ni en la validación de la utilidad, sino en la comprensión comunicativa del sentido de la realidad que, paradójicamente, algunas teorías feministas no comparten.

Otros datos y eventos consignados han sido tomados principalmente de Giedion (1940), Churchill (1945), Habermas (1962), Sennett (1974) y Pascoe (Ed.; 1974).

(14) Ciertamente, las fechas y hechos empíricos no son importantes, porque en general los datos son sólo ejemplos de la teoría, pero no verifican ni prueban nada. Lo que aquí importa es la comprensión de la vida colectiva, y esto se basa no en datos precisos, sino en significados verosímiles; como decía Wundt, se busca la probabilidad psicológica. Así, los datos consignados en este trabajo son arbitrarios, y pueden ser sustituidos por otros o eliminados del todo, porque en conjunto ninguno es importante; el argumento se sostiene sin ellos; lo que sí es importante, en cambio, es que haga sentido la idea de la génesis y presencia de diversos espacios comunicativos como forma de pensamiento y afectividad de la colectividad.

(15) En urbanismo, Lavendan habla de una «ley de persistencia del plano», según la cual, aunque las edificaciones se arruinen o desaparezcan, el trazado original permanece; por ejemplo, citando a Churchill: «los edificios se hacen obsoletos y se destruyen, o se caen, pero la tierra debajo permanece. "La calle que se llama Derecha" permanece en Damasco, y aunque el palacio del César no existe más, los turistas pueden decir correctamente, "por esta calle caminó el César" » (1945, 
p. 6). Asimismo, desde el punto de vista de una psicología colectiva, puede plantearse que los objetos donde está depositada la memoria colectiva son mucho más sutiles que los burdos souvenirs del pasado. En efecto, los objetos pueden ser de dos maneras: existen las cosas, que son objetos llenos, como una estatua o una mesa, donde no se puede estar dentro, sino sólo verlos desde el exterior y rodearlos, y por lo mismo son bastante obvios; pero existen otros objetos, como los espacios, que son objetos vacios, vanos, que parece que no existesn porque uno se encuentra dentro de ellos, es decir, que son aire construido y distribuido, que no se ve pero que sin embargo se habita y se usa especialmente con el movimiento, y que es responsable de una especie de estética afectiva, que se siente pero no se conoce. La memoria colectiva se encuentra en las cosas y en los espacios, ciertamente, pero lo que mejor persiste intacto, sin ser manoseado, expuesto, ideologizado, es lo que pasa inadvertido, y esto son los espacios, de donde se puede concluir que una gran parte del espíritu colectivo está hecha de huecos, de intersticios, de recovecos. No son tanto las paredes, sino el espacio construido entre ellas lo que está pensando, la no pared, de la misma manera que en una conversación lo más significativo es lo que no se dice entre lo que se está diciendo, como por ejemplo las pausas y silencios, las entonaciones y gestos, porque ahí radican los dobles significados, los ánimos y el objetivo mismo de la comunicación. Ciertamente, la cultura cotidiana es la cultura que queda entre los huecos de lo que se considera cultura.

Por lo demás, el concepto de Memoria Colectiva es original de Maurice Halbwachs (cfr. 1925, 1950), totalmente distinto al concepto homónimo de C. G. Jung. Se refiere a la reinterpretación del pasado que las sociedades realizan para poder comprender su propia realidad y elaborar sus proyectos de futuro. Se construye simbólicamente el pasado de la misma manera que se construye el futuro y el presente. Asimismo, las reconstrucciones sucesivas de la memoria colectiva se llevan a cabo mediante la configuración y reconfiguración de los espacios significativos de la colectividad (cfr. vgr. 1941).

\section{Referencias}

Bell, D. (1987). «La vanguardia fosilizada». Vuelta. México, N. . 127; junio 1987.

Billing, M. (1987). Arguing and Thinking. A Reetorical Approach to Social Psychology. Cambridge; Cambridge University Press.

Churchill, H. S. (1945). The City is the People. New York; Reynal and Hitchcock.

Descamps M-A. (1979). Psicosociología de la Moda. México; Fondo de Cultura Económica. 1986.

GEHL, J. (1987). Life Between Buildings. Using Public Space. New York; Van Nostrand Reinhold Co.

Giedion, S. (1940). Espacio, Tiempo y Arquitectura (El Futuro de una Nueva Tradición). Barcelona; Editorial Científico-Médica. 1958

Giedion, S. (1952). «Historical background to the core», en: J. Tirwhitt, J. L. Sert, E. N. Rogers: The Heart of the City. New York, Pellegrini and Cudahy, Publishers.

González Rodriguez, S. (1988). Los Bajos Fondos. La Bohemia, el Antro y el Café. México; Cal y Arena.

Habermas, J. (1962). Historia y Critica de la Opinión Pública. La transformación Estructural de la Vida Pública. Barcelona; Gustavo Gili. 1981.

Habermas, J. (1968). Ciencia y Técnica como Ideología: Madrid; Tecnos. 1984.

Halbwachs, M. (1925). Les Cadres Sociaux de la Mémoire. París; Presses Universitaires de France.

HalbwaChs, M. (1941). La Topographie Legendaire des Evangiles en Terre Sainte. Etude de Mémoire Collective. París; Presses Universitaires de France.

Halbwachs, M. (1952). La Mémoire Collective. París; Presses Universitaires de France. 1968.

Huizinga, J. (1937). Homo Ludens. Madrid; Alianza. 1972.

PAscoe, L. C. -editor- (1974). Enciclopedia of Dates and Events. London; Teach Yourself Books.

Sennett, R. (1974). El Declive del Hombre Público. Barcelona; Península. 1978.

TARDE, G. (1898). «Opinion and conversation» en On Communication and Social Influence. The University of Chicago Press. 1969.

Viqueira Albán, P. (1987). ¿Relajados o Reprimidos? Diversiones Públicas y Vida Social en la Ciudad de México durante el Siglo de las Luces. México; Fondo de Cultura Económica. 